\title{
Los Apuntes de los alumnos: estilos, usos y sentidos en la construcción del conocimiento*
}

Ana M. del Pilar Pérez.**

\section{Resumen}

El presente artículo, síntesis sobre la investigación realizada en el marco de la tesis de Maestría en Educación, pretende posibilitar una visión más amplia de la toma de apuntes- note taking -, a nivel terciario, reconocido soporte en el acercamiento al conocimiento. La dinámica de los apuntes es explorada en profundidad abordando: estilos, modelos, usos, y esencialmente, la implicancia que podrían tener en la construcción del conocimiento, promoviendo conceptualizaciones, o beneficiando su adquisición. Comprendemos que, las categorías reconocidas que hacen a la "sustantividad y claves"ubicadas en la dimensión "Contenidos" entre otras, no se agotan en su contexto. Reconocemos la vinculación de los apuntes con diferentes aspectos del contexto anotador, e identificamos como central su relación con" estrategias de fondo" y" pausa reflexiva". Aspiramos fecunden en una toma de apuntes que canalicen la elaboración de constructos genuinos en nuestros jóvenes. Finalmente, nos cuestionamos respecto al lugar que les correspondería en la agenda didáctica, empeñados en optimizar las prácticas de los estudiantes.

\begin{abstract}
The present article, synthesis about the research carried out in the frame of the thesis of Master in Education, aims to provide a wider view of students'note taking at a college level and recognized support of the approach to knowledge. The dynamic of note taking is deeply explored involving: Types, modes, and different uses and, essentially, the influence they may have in the construction of knowledge, i.e. if they promote conceptualizations or benefit the acquisition of knowledge. We understand that the identified categories such as "sustantivity and clues" positioned in the dimension "Contents" among others, are not exhaustive. We recognise the relationship of note taking with different aspects of its context and identify as crucial its connection with "ground strategies and reflexive pause". We hope it prolific in a note taking strategy which may lead to an elaboration of authentic constructs in our young. Eventually, we ask ourselves about the place that note taking may have in the pedagogical agenda to improve students' practices.
\end{abstract}

\section{I ntroducción}

Y... bien... ahora lápiz y papel en mano y a tomar notas...", los alumnos prestos se dedican a copiar textualmente lo que figura en la pizarra, o expresa el docente.Este comentario de un profesor cuestionado respecto a "apuntes de los alumnos"daría lugar a muchos planteamientos.

La situación, se produce, quizás, con demasiada frecuencia en los contextos áulicos y ocupa un tiempo relativamente extenso de la permanencia del alumno en su clase. Sin embargo, ¿Es siempre así? ¿Cómo se llevan a cabo? ¿Cuál es el sentido de la toma de apuntes de los alumnos? ¿Cuál es el o los objetivos? ¿Se cumple con los mismos?, ¿Qué piensan los alumnos respecto a sus notas? ¿Cuál es el efecto de los mismos en la estructuración del conocimiento? 
¿Por qué este tema? Porque creemos que los apuntes tienen atributos que van más allá de ellos mismos, es decir que trascienden su propia modalidad, por estar relacionados no solo a estrategias y estilos de aprendizaje, sino que también refieren a la historia del estudiante: a cursos previos, a experiencias académicas, al enfoque del docente en su desempeño de aula, a la propia valoración del estudiante, e inclusive se extienden a la vida cotidiana, en la que la presión ejercida por el conocimiento lleva a una necesidad de desarrollo de aptitudes selectivas de un modo rápido y eficiente. De modo que, la toma de apuntes se proyectaría del clima de aula a ámbitos sociales, acrecentando la justificación de la relevancia del tema. La elección se hace además por considerarse un tema poco transitado, aunque pertinente, ya que las notas pueden constituir un valioso elemento en la estructuración del conocimiento del alumno.Es claro que de ser así, sería un tópico de interés y notabilidad para docentes en general e inclusive para los propios alumnos.

Entendemos oportuno aclarar que se utiliza el término apuntes, en lugar de notas, por prestarse este último a confusiones con calificaciones, sin embargo, en los textos de lengua inglesa a los que hacemos referencia posteriormente, se emplea el vocablo "note taking". Igualmente se utiliza, esporádicamente, el término "notas" como forma de variar el léxico empleado, pero recordando siempre que su connotación es la de apuntes.

\section{Los apuntes en el saber de aula como objeto de estudio}

El propósito del presente trabajo ha sido indagar sobre los "apuntes de los alumnos", motivados por una mirada docente que constantemente cuestiona respecto a lo que ocurre "del otro lado": qué ocurre cuando están en el contexto del aula y se dedican con esmero a tomar notas. Es así, que nos preguntamos si no estamos frente a una estrategia considerada al margen de las estrategias pensadas como de aprendizaje.

En este lineamiento de propósito, hemos apuntado a:

* Indagar en contextos áulicos de Instituto de Formación Docente

* Conocer cómo son estructurados y descubrir las posibles razones de su implementación

* Conocer el pensamiento del alumno al respecto.

* Comprender el fenómeno: "Apuntes de los alumnos" a efectos de ampliar el conocimiento de su incidencia en la construcción del conocimiento.

Esta multiplicidad de cuestionamientos se encuentra enmarcada en dos preguntas esenciales las cuales han conjugado amplitud y focalización.

1. ¿Perciben los alumnos relaciones entre sus apuntes y la construcción del conocimiento?

2. De ser así, ¿los apuntes estructurados reflexivamente podrían proporcionarles mayor beneficio en la construcción de sus conocimientos?

Es válido aclarar que no se pretende realizar juicios valorativos referentes a las formas o modelos, y si consideramos el modo de documentar algún tipo de información con carácter autodirigido y consciente.

Se entrevé una problemática que pone en juego al estudiante y a su actividad de registro de apuntes, en un plano de conciencia respecto a la relación entre éstos y su implicancia en la construcción de su conocimiento. Efectivamente, no se vislumbran respuestas claras y es precisamente, esta ausencia, lo que justificaría el trabajo de investigación. 


\section{Lineamientos teóricos}

Se realizó la revisión de la literatura existente desde 1920 con Crawford, hasta Monereo 2003 pasando indefectiblemente por Kenneth Kiewra, avezado en la temática. En el recorrido de las líneas teóricas es posible distinguir dos aspectos: Por un lado, evidenciamos la presencia de estudios que refieren a la clasificación de diversidad de estilos, multiplicidad de usos y variedad de fases en relación al proceso mismo de la toma de apuntes. Por otro lado, la revisión de la literatura, teniendo como objetivo el foco de atención sobre las finalidades que tendrían los apuntes, observamos que este se ha trasladado, desde un registro de características más tradicionales, a una anotación que entendemos que acompasa los cambios en paradigmas de una Educación Transformadora ${ }^{1}$.

Observando los años de la realización de los estudios podríamos decir que se están incorporando paulatinamente abordajes de investigación que ensayan superar reduccionismos característicos de perspectivas más clásicas a través de no solo reconocer estilos sino de analizar los procesos desde una visión alumno-estilos y su relación con el aprendizaje. En general podemos afirmar que la toma de apuntes como tema de investigación ha sido tratada aunque, no exhaustivamente, en países como España, Méjico, USA e Inglaterra, sin embargo, no se ha encontrado literatura proveniente de nuestras latitudes.

Se constata, de todos modos, una realidad compartida por estudiantes de diferentes contextos e inclusive diferentes tiempos, que han manifestado de modo natural el no poseer instrucción respecto a la forma más efectiva de hacer uso de dicha herramienta de aprendizaje.Varios espacios académicos, hoy día están implementando cambios al respecto; instituciones de niveles terciarios y universidades están instrumentando, en forma creciente, dichas instancias, como forma de equipar a los estudiantes con habilidades académicas de supervivencia tales como toma de apuntes e investigación bibliotecaria.

La oportunidad de lograr la comprensión de una de las formas por las cuales el alumno se hace del conocimiento sería, entonces, la investigación de la toma de apuntes, considerándola como una de las tareas en la que se encuentran frecuentemente involucrados en el quehacer de aula. De modo que si nos acercamos a comprender dicha experiencia podríamos incrementar las luces sobre cómo se realiza la adquisición de conocimientos a través del registro de apuntes ${ }^{2}$. Sin duda, es de consenso general que el aprendizaje exige un esfuerzo personal e intransferible, cada individuo aprende a su peculiar modo, a su ritmo, responde a sus intereses y motivaciones. En tal sentido, una de las formas de aprender es el estudio, entendido como esfuerzo, que se aplica a la comprensión y adquisición de conocimientos. En este campo podríamos ubicar a los apuntes como una de las herramientas más comunes y generalizadas que tienen los estudiantes a su alcance desde tiempos muy remotos, para acceder al conocimiento ${ }^{3}$. En distintas situaciones el aprendiz accede al conocimiento de distintas maneras ya sea por asociación o construcción según lo amerite la circunstancia en una suerte de integración jerárquica en"distintos sistemas alternativos de análisis de una misma actividad de aprendizaje". Pozo, (1995,66/68). En este orden, el aprendizaje constructivo está más dirigido a dotar de significado un material, a tener determinada organización.

¿Existen, o no, beneficios en la toma de apuntes ¿Favorecen la memoria o permiten realizar algún tipo de construcción del conocimiento? Partimos de un hecho claro, corroborado por la práctica cotidiana, los alumnos sí creen en la toma de apuntes, dado que la gran mayoría, por no decir todos, asisten a charlas, clases, portando lapiceras y papel como elementos fundamentales de la actividad. Sería entonces ¿un buen antídoto contra el olvido?; O ¿habría otras causas? Sin embargo, su utilidad o beneficio, es decir, si ayuda o no a recordar el material de las aulas y colabora en la construcción del conocimiento, ha sido y es, controvertido. 
El fenómeno de la toma de apuntes, entraña diversos aspectos cognitivos que entran en juego durante su realización. Comenzamos por reconocer la existencia de determinadas fases o etapas a tener en cuenta, como también percibimos la presencia de ciertos patrones o caracterizaciones en el rol del anotador. Se trabaja con el discurso docente primordialmente oral, y en esta etapa es cuando el alumno hace su toma de decisiones con respecto de realizar anotaciones literales o con carácter interactivo. Podríamos decir que, la toma de apuntes tendría diferentes niveles: por un lado, simplemente "decodificar el código lingüístico", donde la información "se prende más que se aprende ". (Monereo, C, 2000,99). Se desprende que, al finalizar la clase los alumnos que trabajan este primer nivel, suelen haber comprendido relativamente menos de lo esperado, "mucho menos de la mitad del contenido" como señalan estudios realizados. Sin duda que, como docentes movidos por el afán de un aprendizaje de dimensiones más duraderas y eficientes, esta situación es altamente preocupante.

En un segundo nivel, el alumno pondría en juego otras dimensiones que hacen al aprendizaje activo, significativo y reflexivo. Al respecto creemos que, solamente comprometidos con una actitud activa de aprendizaje, acompañando una anotación también de iguales características, sería posible remediar la simple decodificación literal. En esta etapa, el estudiante anota o registra propiamente la información. Toma decisiones de qué modelo adoptar y cómo hacerlo, siguiendo uno o varios modelos. Entramos entonces al dilema de la postura del alumno, es decir ¿es consciente de cómo lo hace, o sigue una rutina?, ¿es reproductor de la información, o construye su conocimiento, lo transforma? Esta instancia se encontraría posibilitada o fomentada por el conocimiento o desconocimiento de modelos 'asueto cognitivo', por parte del alumno ${ }^{4}$.

Considerando, a la toma de apuntes, dentro de las "estrategias" de carácter cognitivo, la entendemos integrada a las de carácter meta cognitivo e interpersonales, en una suerte de tapiz donde las fibras se entrecruzan, creando imágenes nuevas, más fuertes y más coloridas. Los apuntes, serían en este sentido, conductas intelectuales determinadas a su vez por el sujeto como ser, su entorno socio cultural y el docente, armonizándose, también, con el objeto de aprendizaje y el tiempo de que disponen. En relación con este aspecto, es interesante el aporte de Nunan, D. quien en un estudio realizado en 1991, encontró que una de las características principales de un buen aprendiz de lenguas era precisamente la habilidad de reflexionar y articular el proceso que sustentaba su aprendizaje.

Durante décadas los alumnos han sido -esporádicamente- orientados a tomar apuntes de carácter lineal, Sin embargo, recientemente se ha descubierto que no es esta la forma más eficaz.

Básicamente, se considera que toman mucho más tiempo y son improductivos. El objeto primordial, al estudiar, debe ser el entender las relaciones entre los temas centrales y los puntos que lo fundamentan, en otras palabras, es necesario tomar apuntes que cooperen con dicha comprensión. Es, sin duda, en esta búsqueda consciente del aprender, que el individuo coloca en juego mecanismos psicológicos, afectivos y sociales, que lo conducen a diferentes actividades de adquisición, exploración y evaluación. En estas selecciones particulares desarrollamos nuestras estrategias de aprendizaje, basándonos en capacidades dominadas para así crear otras nuevas. En este orden, es importante que los alumnos identifiquen su percepción de estrategias y establezcan las correlaciones entre estilos de aprendizaje y las respectivas estrategias como también que consideren todos los elementos a pensar y o incluir en sus notas. 
Si bien el presente estudio refiere a los apuntes de los alumnos, entendemos que no se debería dejar de percibir el aula como un todo con la presencia del docente y su rol al respecto en por Ej. Proporcionar una visión general al comienzo de la clase o charla, organizando el material de un modo lógico, especialmente si es complicado. Cuidar o controlar el ritmo, ya que los alumnos toman notas a una velocidad de aproximadamente 20 palabras por minuto, mientras que un conferencista lento habla a una velocidad de $\mathbf{1 0 0}$ palabras por minuto. De modo que seria conveniente detenerse con determinada frecuencia a efectos de que los alumnos puedan lograr alcanzar al docente en su discurso.

\section{Los apuntes y las consideraciones metodologicas}

La elección de la metodología supone un paso muy importante en todo proceso de investigación, y requiere un cuidadoso análisis de: cómo enfocamos los problemas; cómo buscamos las repuestas a nuestras preguntas de investigación; cuáles son los supuestos y el propósito que completan nuestra visión conceptual.

La decisión al respecto ocupó diversas etapas: al principio, luego de la reflexión y selección del paradigma, se realizó la preparación del proyecto, procediéndose a la tarea de optar por las diferentes estrategias metodologicas a utilizar, como también selección de casos, contextos $y$ fechas.

Selección de paradigma. De modo que, a partir de la propia visión conceptual, definimos al proceso como de carácter inductivo, partiendo del estudio de los apuntes en su contexto, con la presencia de factores simultáneos y emergentes que llevaron a la elaboración de las categorías y dimensiones. En esta procura de las palabras y comprensión de las conductas de las personas sometidas a la investigación, es donde el problema necesita ser explorado, pues la información previa, está ausente o es escasa y limitada -como en nuestro caso-, las variables son desconocidas o difícilmente consideradas en el punto de partida. Se destaca la importancia del contexto, el cual puede dar forma al entendimiento del fenómeno en estudio: los apuntes. En el marco de un paradigma de corte cualitativo con carácter de apropiativo y aproximativo, y que a su vez encuadre aspectos de teorías de aprendizaje y psicología cognitiva, se establece la metodología adecuada al trabajo. Este diseño predominó en la investigación sin descartar la posibilidad de un enfoque ecléctico, cuanti-cualitativo en el uso de determinadas técnicas, al instrumentar, en la fase de acercamiento, el cuestionario, como forma de aproximación a la selección de casos.

El estudio, definido como un proceso de búsqueda de comprensión de un fenómeno humanosocial intenta crear una visión holistica de los apuntes y conducir el trabajo de campo dentro del marco conceptual establecido.

Selección de contextos y casos. La selección de contextos se realiza mediante un primer criterio de heterogeneidad, con el objeto de abarcar tipos diferentes y un segundo criterio que hace al pragmatismo o sea posibilidades de acceso. El Instituto de Formación Docente"Maria Orticochea" de la ciudad de Artigas (Uruguay) se encuentra enclavado en una zona relativamente apacible y cercana. Dentro de dicho Instituto se trabaja con los segundos años, dada su experiencia en la institución y sobre la base de un criterio de dispersión se procuró encontrar una muestra que enriquezca el estudio, y contactar un cierto número de casos tratando de abrir el abanico al máximo. Uno de los dispositivos con que se ha contado para crear la diversidad ha sido la palabra de los docentes a cargo del grupo, que cooperaron en la selección de casos, a efectos de trabajar con estudiantes con diferente actitud frente al aprendizaje, grados de atención e intervención, como también variada calificación. 
Selección de fechas. Hemos entendido oportuno realizar el trabajo de campo durante los meses de agosto, septiembre, octubre, noviembre y diciembre, aunque la elaboración del proyecto de tesis se inició en el mes de enero previo, pues entendemos que es pertinente un acercamiento cuidadoso y paulatino.

Selección de instrumentos.Respecto a los instrumentos de recolección de datos -nos referimos a estrategias pues comprenden más de una técnica-,se ha trabajado con "estudio de casos". En los mismos se pretende explorar, trabajando con datos primarios, recogidos por el propio investigador, un fenómeno especifico "caso" limitado en el tiempo y acotado al contexto. Finalmente, hemos focalizando la audiencia hacia la cual orientamos el trabajo: alumnos y docentes, para así poder legitimar la metodología.

Instrumentos: Se usan a tales efectos: *Observaciones *Cuestionarios *Documentos *Entrevistas semi-estructuradas.

Se ha realizado observación de tipo externa o sea no participante, sin embargo, se es proclive a lograr un clima amigable y una actitud que favorezca un buen "rapport". Se obtienen los datos a través de la observación directa en primer lugar, y a tales efectos se emplea una planilla guía, cuaderno de notas, notas de campo, las cuales cooperaron como facilitadoras y coadyuvantes en la decisión muestral. La observación semi participante se ha desarrollado tratando de no incursionar en formas obstrusivas, como también aportar el clima adecuado para las próximas técnicas a utilizar: completar cuestionarios, solicitar documentos -apuntesy realizar las entrevistas que se consideren pertinentes.

El cuestionario, incluye ítemes relativos a cuatro macro componentes de la actividad realizada o no por los alumnos: decisión en la toma, ausencia del registro, selección, valoración y espacios de instrucción formal. Resultan así, 27 ítemes a los cuales se les ha añadido otros más específicos dentro de ellos mismos. El resultado es un cuestionario de 50 ítems que toma en cuenta los aspectos básicos de la toma de apuntes. Los diferentes puntos incluyen respuestas afirmativas o negativas, selección simple o multivariada, como también la solicitud al alumno de que agregue el o los comentarios que considere pertinentes. Tres de los apartados presuponen la existencia del registro de apuntes, mientras que uno presupone que no se produce dicha actividad y se intenta indagar sobre las posibles causas.

Por otro lado, entendemos valioso utilizar análisis de documentos: apuntes con un sesgo clásico, realizando una exploración de carácter interno y externo que permita determinar temas básicos y también las interrelaciones entre ellos.A tales efectos se seleccionan 8 alumnos y se les solicita notas de diferentes áreas, considerando algunos aspectos que creemos cooperan en la riqueza de la muestra: "copista total", "copista parcial", apuntes con información relevante, y con modelos específicos.

Partiendo de las interrogaciones más generalizadoras del cuestionario, las preguntas de la entrevista semi estructurada han mantenido un propósito más específico y refieren al significado de los hechos y actividades en que están las personas, como también se han elaborado preguntas que refieren a la influencia del contexto físico y social.Fig 1 Simultáneamente, y con el propósito de una visión más completa, se fue redactando el diario del investigador en el cual se registraron además de cronologías de todo el trabajo, las opiniones, emociones y comentarios del investigador, así como también se dio la posibilidad de anotar lo latente y muchas veces no observable.La multiplicidad de instrumentos nos ha permitido respaldar la información, haciendo uso de la llamada" estrategia de triangulación".

\section{4 - Universidad ORT Uruguay}




\section{FASES DEL PROCEDIMIENTO}

OBSERVACIÓN DE AULAS<smiles>C1CCCCC1</smiles>

CUESTIONARIOS
Planilla guía

Clases presenciales

2 secuencias: módulo

1h.y 45

Grupo $2^{\circ}$ año IFD.

22alumnos.

28 apartados

50 ítemes

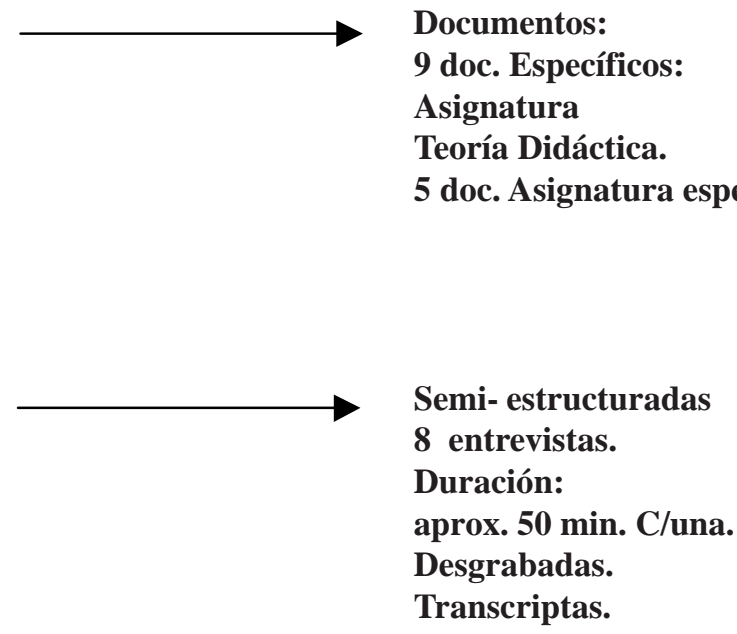

Fig. 1.Fases del procedimiento

La reconstrucción de los apuntes en la práctica cotidiana

La práctica cotidiana en las aulas revela la presencia innegable de apuntes; creemos que la posibilidad de acceder a su reconstrucción nos podría acercar al conocimiento del alumno como persona y su potencialidad como estudiante y así optimizar su tiempo de estudio. ${ }^{5}$

Lo que hacen los alumnos en los apuntes.

A medida que se avanza en la investigación, se han ido elaborando dimensiones de análisis que podrían ser de interés para el estudio, como por ejemplo: Contexto de anotación. Refiere precisamente a la existencia de determinadas recurrencias de lo observado en el aula y que revela la presencia de un espacio específico y claramente presente.

Nuestro primer abordaje da cuenta de determinadas características que consideramos se perciben en el cuadro que aparece a continuación: Fig. 2 


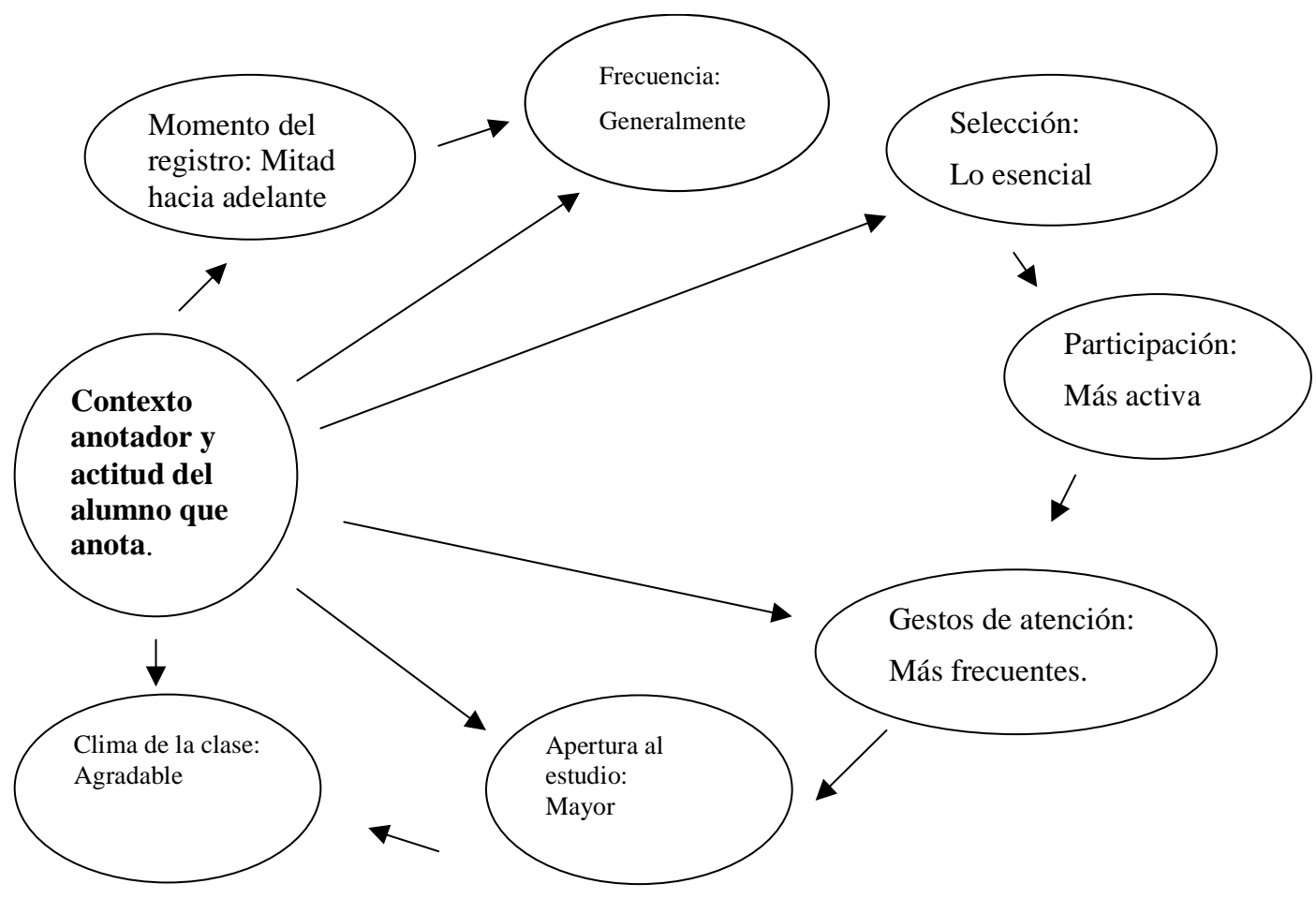

Fig.2 Contexto anotador y actitud del alumno que toma apuntes.

En la observación de aula percibimos que no todos toman apuntes pero sí la mayoría, lo cual nos lleva a pensar que, efectivamente, es una actividad a la que se le dedica tiempo y, quizás, bastante esfuerzo. De los 22 alumnos presentes, 18 registran notas.Respecto a los momentos de registro, observamos que pocos anotan al comenzar, como que esperaran indicaciones del docente, sin embargo, hacia la terminación de la actividad, se preocupan por tomar más notas como para no perderse el gran final.Se percibe que varios de los que anotan, parecen pensar en cómo hacerlo y otros más bien lo hacen en forma mecánica. Se observa que los alumnos que no toman o que toman pocas notas son, curiosamente, los que menos intervienen. Sin embargo, los que toman notas parciales o totales son los que intervienen en forma más frecuente. Es precisamente el contexto anotador el que comienza a dar forma al entendimiento organizativo del problema, como también soporte a nuevas interrogantes.

En la segunda visita de observación se verifican las recurrencias y se percibe clima de tranquilidad y trabajo compartido, aceptando la presencia del investigador de modo muy satisfactorio e inclusive varios manifiestan claro deseo de cooperar en el estudio.Se entregan y completan los cuestionarios.

Un vez con los cuestionarios en mano, se inicia la primera etapa de análisis, con la correspondiente lectura primaria, luego exhaustiva en procura de respuestas interiorizándonos en lo que se procura describir, responder y,o descubrir. Se analizan los cuestionarios aplicados a la totalidad del grupo, por medio de los que se intenta responder a los objetivos de identificar anotadores, reconocer contenidos y modelos organizacionales ypara percibir su alcance como herramienta de aprendizaje. Los datos orientan a las diferentes formas que manifiestan adoptar 
Ios alumnos como por ejemplo: apuntador total o parcial; anotador lineal o con utilización de esquemas, un número muy elevado expresa que sí, que efectivamente registran notas, con cierto tipo de modelos. Referente a la cuestión de "personalización", se logró identificar a algunos que integraban formas personales, abreviaturas, comentarios, reflexiones que obran en pro del aprendizaje o algún nivel de diálogo consigo mismo.

Como se observa en la gráfica 3 el número de alumnos que anota es superior al que no lo hace, lo cual, sin duda, explica lo que todos podemos apreciar en múltiples contextos áulicos de nivel terciario, e inclusive universitario, y /o en diferentes tipos de conferencias, seminarios: Un 82\% expresa su opción por tomar apuntes en clases.

El análisis de los cuestionarios es sumamente revelador de datos cuantitativos, que se presenta a continuación como forma de ampliar el panorama descriptivo. La gráficas presentadas en Fig. 3 y 4 ilustran algunos de los aspectos identificados, mientras que la lectura de otros datos se expresa en forma porcentual. El resultado del análisis de los cuatro macro componentes propuestos revela:

1-Decisión en la toma de apuntes: en la opción por anotar $\mathbf{8 2 \%}$ se contrapone al $\mathbf{1 8 \%}$ que no lo hace y cuestionados sobre las causas: $10 \%$ manifiesta no poder seguir el ritmo de la clase; $\mathbf{1 2} \%$ prefiere escuchar; $\mathbf{3 8 \%}$ elige apuntes de compañeros; $\mathbf{3 0} \%$ reconoce no saber tomar y $10 \%$ opta por leer el texto.

2-Selección en la toma de apuntes: Del $\mathbf{8 2} \%$ que sí toma notas, $\mathbf{9 \%}$ revela ser copista total, $\mathbf{8 2} \%$ menciona anotar lo esencial, y $\mathbf{9 \%}$ ser copista parcial .Respecto a la frecuencia, $46 \%$ expresa anotar siempre, mientras que $\mathbf{4 1 \%}$ anota generalmente y $32 \%$ ocasionalmente. Respecto a la utilización de modelos solamente $32 \%$ expresa utilizar y $77 \%$ no contesta expresan inseguridad o evitan evidenciar desconocimiento.

3-Valoración: en el uso del tiempo áulico.Es interesante observar que el 73\% considera que es buen uso de su tiempo,el $\mathbf{2 7 \%}$ expresa que es un óptimo empleo de su tiempo en el aula y $0 \%$ manifiesta considerar a la toma de apuntes como pérdida de tiempo. Respecto a la valoración y usos en el aprovechamiento, un $36 \%$ considera muy provechoso estudiar de sus notas, $\mathbf{5 5} \%$ provechoso, y $\mathbf{9 \%}$ poco provechoso. Teniendo en cuenta el uso que le dan sus apuntes, la mayoría $\mathbf{6 8 \%}$ expresa que realizan lectura casi inmediata de los mismos, $25 \%$ los lee después de mucho tiempo y $7 \%$ expresa no utilizarlos o no entenderlos a posteriori. Dicho criterio está interrelacionado a la autovaloración, en la cual un $\mathbf{5 0 \%}$ los cree valiosos. Referente a la comprensión de apuntes ajenos un $\mathbf{6 8}$ \% los considera como poco entendibles, mientras que alrededor de la mitad los cree inteligibles. Teniendo en cuenta el grado de comprensión que les dan a sus apuntes, la mayoría, $\mathbf{6 8 \%}$ los considera como poco entendibles, mientras que alrededor de menos de la mitad los cree inteligibles.

4-Referente a Instrucción: 95\% menciona no haber recibido ningún tipo de orientación, y el restante $\mathbf{5 \%}$ manifiesta ser autodidacta. Por otro lado, $\mathbf{7 3} \%$ como lo indica el gráfico estaría interesado en recibir instrucción formal, mientras que $4 \%$ no contesta y $\mathbf{9 \%}$ no tendría interés. Fig., 6 
Gráficas 3, 4.

\begin{tabular}{|c|c|c|}
\hline OPCIÓN PARA TOMAR APUNTES & 18 & $82 \%$ \\
\hline OPCIÓN POR NO TOMAR & 4 & $18 \%$ \\
\hline
\end{tabular}

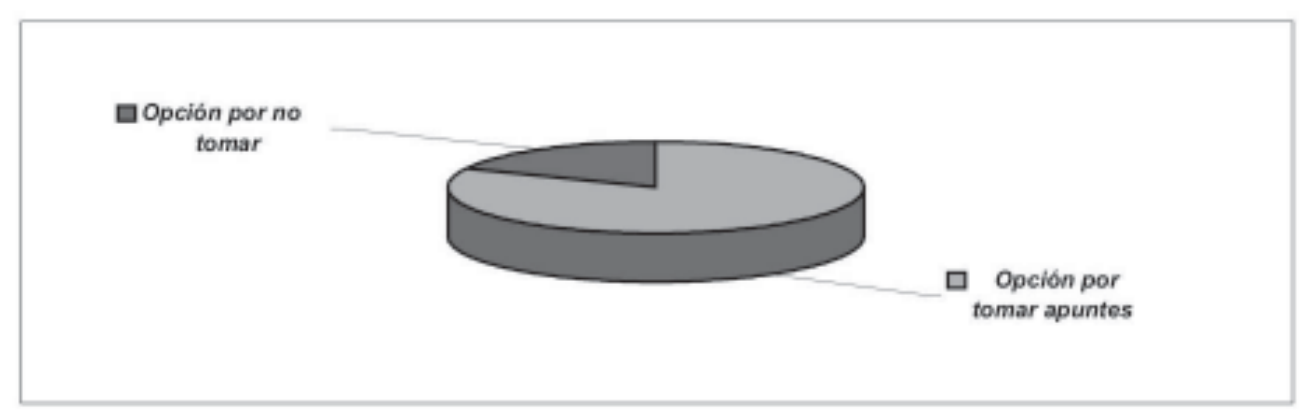

\begin{tabular}{|c|c|c|}
\hline FORMATOS & & \\
\hline MODELOS & 5 & $23 \%$ \\
\hline NO CONTESTA & 17 & $77 \%$ \\
\hline
\end{tabular}

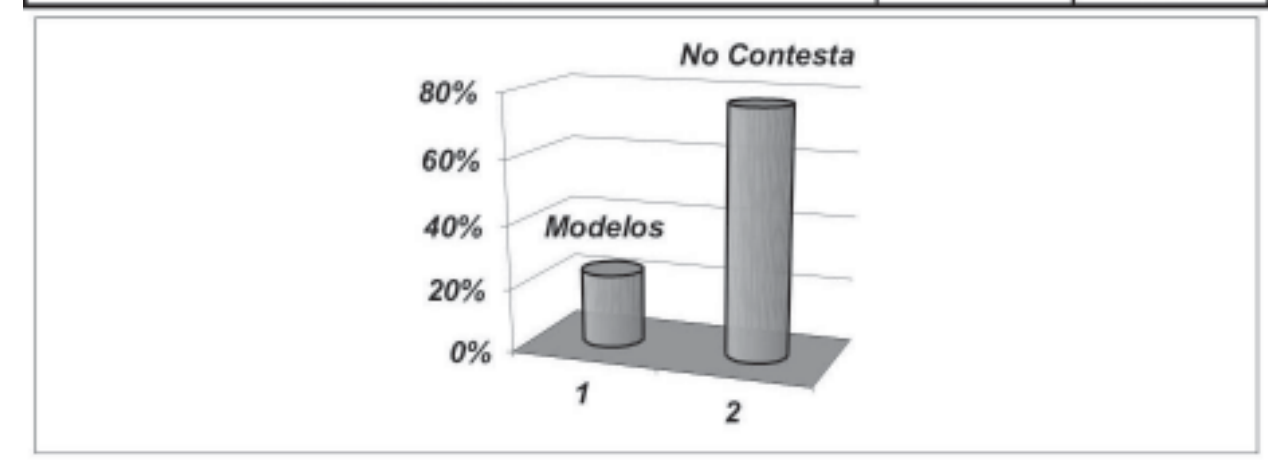

\begin{tabular}{|c|c|c|}
\hline VARIABLE DE VALORACION - TIEMPO & & \\
\hline PERDIDA & 0 & $0 \%$ \\
\hline BUEN USO & 16 & $73 \%$ \\
\hline OPTIMO USO & 6 & $27 \%$ \\
\hline
\end{tabular}

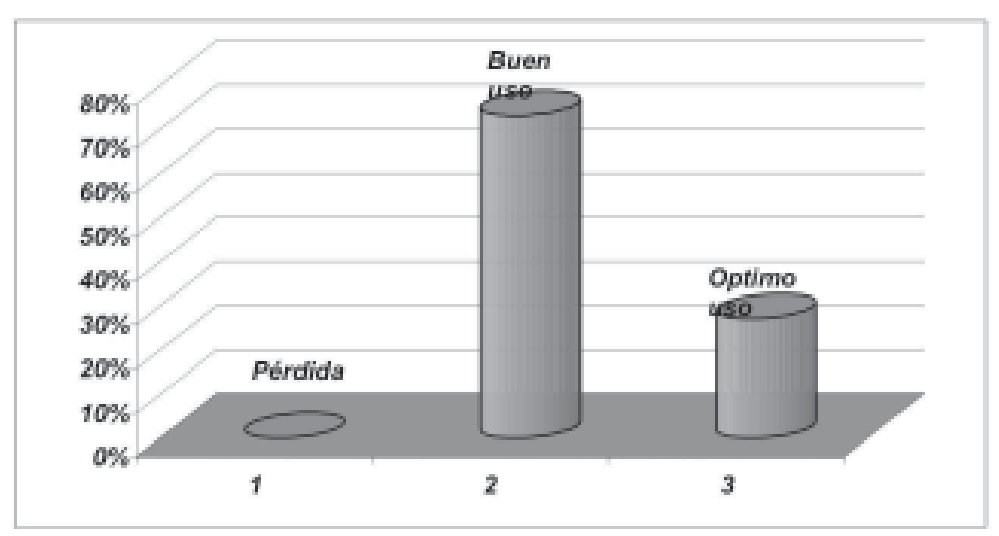

38 - Universidad ORT Uruguay 


\section{Graficas 5 y 6.}

\begin{tabular}{|c|c|c|}
\hline VARIABLE ASPIRACIÓN & & \\
\hline INTENCIÓN DE RECIBIR INSTRUCCIÓN & 16 & $73 \%$ \\
\hline SIN INTENCIÓN & 2 & $9 \%$ \\
\hline NO CONTESTA & 4 & $18 \%$ \\
\hline
\end{tabular}

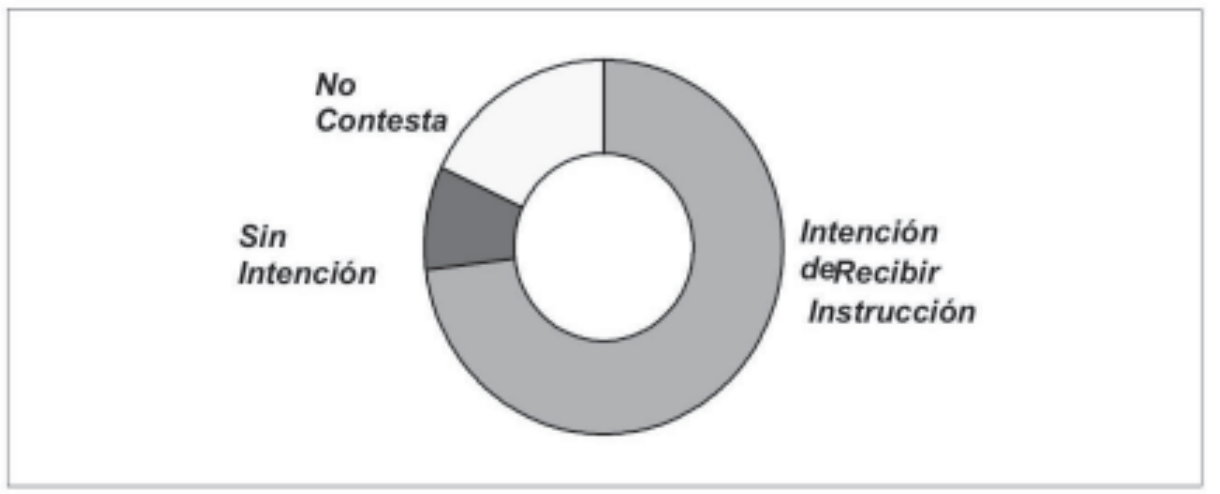

El análisis de la composición de la anotación escrita-documentos-apuntes- nos ha permitido elaborar una tabla referencial con los diferentes aspectos que los integran, clasificando en ellos los distintos registros.Fueron igualmente analizados, según los objetivos planteados, los siguientes referentes a verificar: estilos, organización, estructuras y contenidos. La elaboración de los códigos y sus referencias nos permitió comprender algo más respecto a la naturaleza de los mismos. La mayoría confirma que no son copistas totales, es decir que anotan todo, que sí son copistas o anotadores parciales, empleando determinados criterios selectivos. Referente a comentarios inferenciales.

Todos manifiestan preocupación por anotar autores, libros, como una forma de respaldo de su conocimiento, posible fuente de estudios posteriores. Referente a su estructura, utilizan algunos esquemas relativamente sencillos, con viñetas, a excepción del anotador 8 , que emplea gran diversidad.Cuando se habla de comentarios personales, éstos prácticamente no existen, excepto una o dos menciones que hacen acerca de si entendieron, o no, la temática. Revelan determinadas situaciones de preferencias, como ser, los que están en el pizarrón, definiciones, citas, frases hechas. Se perciben pocas anotaciones de ejemplificaciones, anotan las informaciones que consideran como verdades.Con respecto al control del espacio, algunos ni lo consideran, se presenta en forma desprolija y desorganizada, con sobresolapamientos, y escritura entre líneas.

A esta altura del análisis nos ha parecido interesante señalar que en conversación con la Prof. del curso se obtuvieron las calificaciones de los alumnos que fueron seleccionados para la muestra. De modo que nos cuestionamos ¿se podría considerar la relación entre los diferentes tipos de apuntes y la calificación del alumno?

Es interesante la percepción de que, justamente los alumnos con mejores calificaciones, son aquellos cuyos apuntes tienen determinadas características: buen control de espacio, utilización de esquemas y diversos organizadores gráficos y lectura legible. Nos preguntamos, en este punto, respecto a la relación que pudiera existir entre los apuntes y la construcción del conocimiento. 
A efectos de ilustrar el análisis de los datos estudiados hasta el momento, se ha elaborado un cuadro que da cuenta de la información recogida en el análisis de los apuntes como registros y un mapa cognitivo al respecto. Tabla 7 y mapa conceptual 8.

El análisis de los datos recogidos a través de los instrumentos: observación, cuestionarios, y análisis de documentos apuntes ha permitido un acercamiento a la descripción de una faceta de la realidad áulica.El primer abordaje de análisis en el que se perciben características o etapas de un continuo y diferentes fases, da cuenta de un contexto anotador y similitudes en los sujetos La presencia del contexto anotador es tan fuerte que remite a un punto de partida enérgico en términos de interés y afán por conocer.

\section{Fig.7.Tabla de análisis}

\begin{tabular}{|c|c|c|c|c|c|c|c|c|}
\hline \multicolumn{9}{|c|}{ Tabla de análisis } \\
\hline \multicolumn{9}{|c|}{ REGISTRO DE ANÁLISIS DE DOCUMENTOS } \\
\hline $\begin{array}{l}\text { APUNTA } \\
\text { DOR }\end{array}$ & $\begin{array}{l}\text { ORGANI } \\
\text { ZACIÓN }\end{array}$ & & $\begin{array}{l}\text { ESTRUC } \\
\text { TURA }\end{array}$ & & $\begin{array}{l}\text { CONTEN } \\
\text { IDOS }\end{array}$ & & TIPOS & \\
\hline $\mathbf{N}^{\circ}$ & $\begin{array}{l}\text { Control de } \\
\text { espacio }\end{array}$ & Fechados & Lineal & $\begin{array}{l}\begin{array}{l}\text { Con } \\
\text { esquem } \\
\text { as }\end{array} \\
\end{array}$ & Esencial & Inferencial & $\begin{array}{l}\text { Copista } \\
\text { Total }\end{array}$ & $\begin{array}{l}\text { Copista } \\
\text { Parcial }\end{array}$ \\
\hline 1 & $\mathrm{~S}$ & $\mathrm{~S}$ & $\mathbf{N}$ & S* & $S^{\circ}$ & $\mathrm{S}$ & $\mathbf{N}$ & $\mathrm{S}$ \\
\hline 2 & $\mathbf{N}$ & $\mathrm{S}$ & $\mathbf{N}$ & S* & $\mathbf{N}^{\circ \circ}$ & $\mathbf{N}$ & $\mathrm{S}$ & $\mathbf{N}$ \\
\hline 3 & $\mathbf{N}$ & $\mathbf{N}$ & $\mathbf{N}$ & S* & $S^{\circ \circ}$ & $\mathrm{N}$ & $\mathbf{N}$ & $\mathrm{S}$ \\
\hline 4 & $\mathrm{~s}$ & $\mathrm{~s}$ & $\mathbf{N}$ & S* & $S^{\circ \circ}$ & $\mathrm{s}$ & $\mathbf{N}$ & $\mathrm{s}$ \\
\hline 5 & $\mathrm{~S}$ & $\mathbf{N}$ & $\mathrm{S}$ & $\mathbf{N}$ & $\mathrm{S}^{\circ}$ & $\mathrm{N}$ & $\mathbf{N}$ & $\mathrm{S}$ \\
\hline 6 & $\mathrm{~s}$ & $\mathrm{~s}$ & $\mathbf{N}$ & S* & $\mathrm{S}^{\circ}$ & $\mathbf{N}$ & $\mathbf{N}$ & $\mathrm{S}$ \\
\hline 7 & $\mathbf{N}$ & $\mathbf{N}$ & $\mathbf{N}$ & S* & $S^{\circ \circ}$ & $\mathrm{N}$ & $\mathrm{N}$ & $\mathrm{S}$ \\
\hline 8 & $\mathrm{~S}$ & $\mathrm{~s}$ & $\mathbf{N}$ & $\mathrm{S}^{* *}$ & $\mathrm{~S}^{\circ}$ & $\mathrm{s}$ & $\mathbf{N}$ & $\mathrm{S}$ \\
\hline 9 & $\mathrm{~S}$ & $\mathrm{~S}$ & $\mathrm{~N}$ & $\mathrm{~S}^{* *}$ & $\mathrm{~S}^{\circ}$ & $\mathrm{S}$ & $\mathrm{N}$ & $\mathrm{S}$ \\
\hline
\end{tabular}

Ref.

$\mathrm{S}=\mathrm{si}$

$\mathrm{N}=$ no $\quad$ Con esquemas: Esencial:

* = esquemas simples $\quad{ }^{\circ}=$ idea completa $\quad * *$ esquema más complejo ${ }^{\circ 0}=$ ideas incompletas (vacíos informativos)

\section{Lo que los apuntes hacen en los alumnos}

Respecto a las entrevistas, en un primer análisis, permitieron reunir profusa explicitación por parte de los propios participantes, de sus propias percepciones con relación a sus vivencias, respecto de la toma de apuntes.Posteriores comentarios y análisis desde la misma subjetividad de los entrevistados complementada con la información que apreciamos rica y profusa coopera en agudizar el pensamiento del investigador y en construir nuevas dimensiones no meramente en el plano descriptivo, sino para comenzar a recorrer un plano más explicativo.

El comportamiento anotador revela determinadas características de los alumnos, e inclusive permite que los mismos interactúen de diferentes modos, ya sea con los contenidos, con sus propios estilos, con el docente, o con su propuesta metodológica. El proceso de anotación apunta a renovar la preocupación por la información, pero dirigida a la construcción de conocimientos y es en ella que se percibe que la toma de apuntes contribuye a la diferenciación de los estudiantes.

\section{0 - Universidad ORT Uruguay}


Fig.8. Mapa conceptual

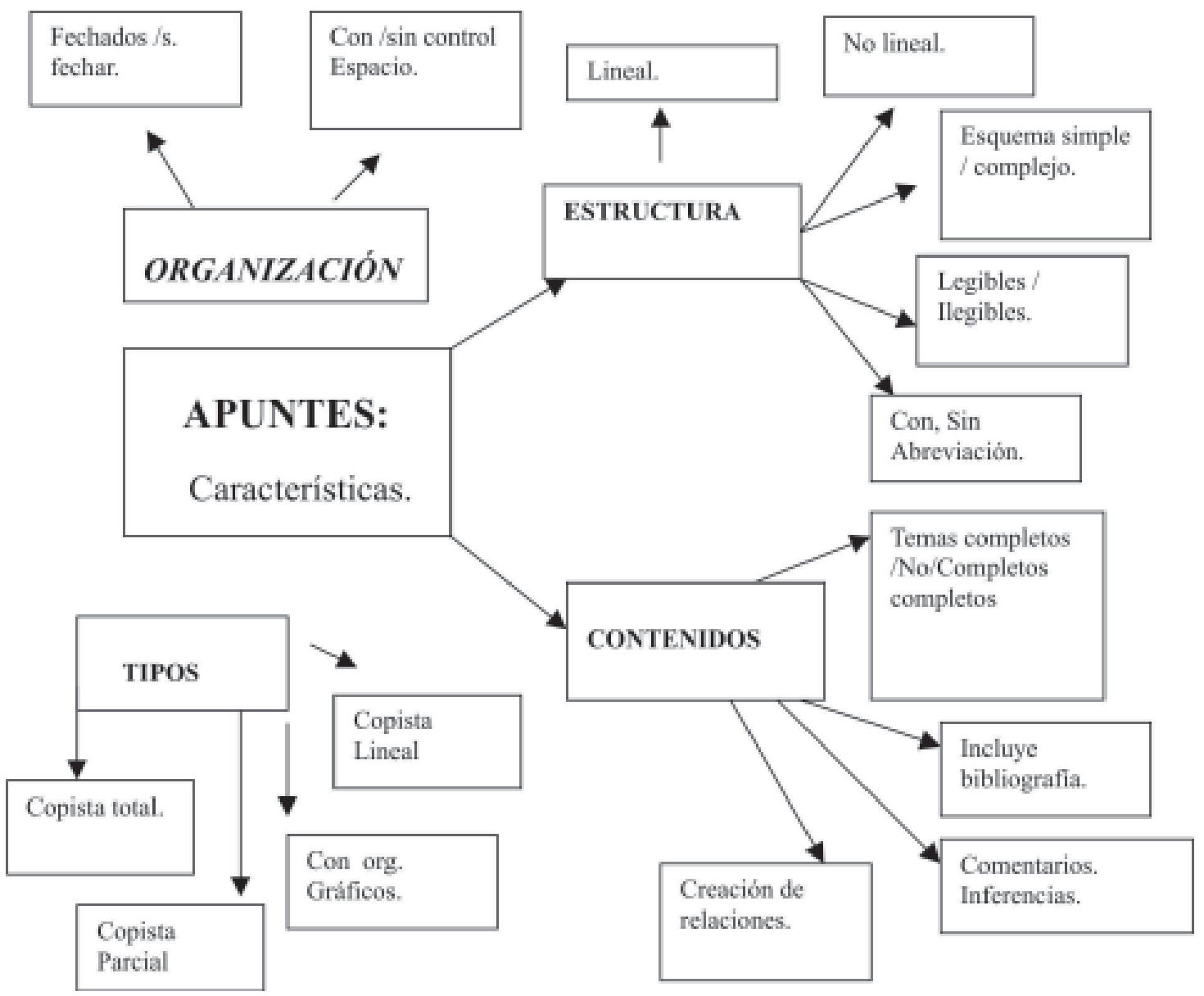

A partir de este plano de estudio más profundo, se han construido las siguientes dimensiones de análisis que permiten visualizar nuevas perspectivas:

Apuntes definidos por su vinculación con el contenido.

Apuntes definidos por su vinculación con el estilo del alumno.

Apuntes definidos por su vinculación con el quehacer docente.

Apuntes definidos por su vinculación a usos y propósitos.

Apuntes definidos por su vinculación con el contenido.

Apuntes por sustantividad.

Nos cuestionamos en este punto, cómo realiza el alumno esa actividad de selección de sustantividad. La comprensión de la propia naturaleza de la temática, la integración de la información que se posee, tanto como el nivel de intervención que se ejerce sobre los procesos cognitivos, estarían interactuando en dicha selección.En múltiples ocasiones el estudiante se guía por lo que considera relevante: trata de dilucidar lo que serían las ideas principales y anota muchas veces tales conceptos en forma textual, como si no quisiera tergiversar el concepto, presentando temores de cambiar o no entender los significados si los cambiara, 
creyendo que la anotación de frases textuales, que hacen a la sustantividad, son disparadores de ideas y de reflexión. En cambio, otros estudiantes, revelan un estado de entrega a la comprensión en forma diferente, pues admiten que pueden mantener los significados utilizando su propio léxico, o sabiéndose capaces de adaptarlo a su manera. Al mismo tiempo expresan que, sus palabras, sus propios términos, lesfacilitan la incorporación e integración de conocimientos ${ }^{6}$.

\section{Apuntes de las claves.}

En este sentido, se aprecia la destreza del alumno para realizar un desbloqueo de su pensamiento inicial, unidireccional, al ver las cosas desde otros ángulos, abandonando la seguridad de un trabajo más dirigido y controlado por una anotación desigualada en términos de actividad abierta y creativa. Realizan un corrimiento de los puntos de vista, de las ideas que el docente destaca y logran abarcar lo que creen como categórico, realizando lo que denominan "anotaciones claves". Al volver a sus anotaciones en forma posterior, son capaces de evocar el contexto de aula, e inclusive, al docente.

\section{Apuntes definidos por el estilo del alumno en clase.}

Apuntes vinculados a estilos de aprendizajes.

En este punto referimos a las características de los seres humanos conjugados con su personalidad como también a sus experiencias de vida, lo cual condiciona que seamos poseedores de determinados estilos de aprendizaje. De hecho, podemos apreciar que el estilo de aprendizaje del alumno coopera en la determinación de la elección específica de modelos ${ }^{7}$.

\section{Apuntes vinculados a la participación activa.}

En nuestro afán por comprender las prácticas cotidianas en la toma de apuntes, constatamos desde las primeras observaciones de aula, que los alumnos que sí tomaban apuntes parecerían participar más activamente, como si estuvieran de algún modo construyendo un diálogo interno entre la mano y la mente que los llevara a intervenir. Dichos aspectos fueron confirmados por los actores del estudio. Admiten, en su mayoría, que la anotación favorece la atención en la temática, evita la dispersión y ayuda, coopera en la concentración y que, por el contrario, el no anotar sí influiría en la posible dispersión de su atención. Sin embargo, al mismo tiempo advertimos que no aparecen registradas sus propias intervenciones o las de sus compañeros, dándole autoridad a la palabra del docente.

Apuntes vinculados a la recepción automática.

En el contexto de anotación, hemos observado comportamientos que denotan seguimiento de determinadas rutinas quizás -en el mejor de los casos-, con el propósito de economizar esfuerzos, ya que el estudiante anota en forma casi literal lo que expone el docente, en una suerte de dependencia instruccional. Y en el peor de los casos, revelarían un desconocimiento casi absoluto de estrategias de aprendizaje o de cómo aplicarlas ${ }^{8}$. 


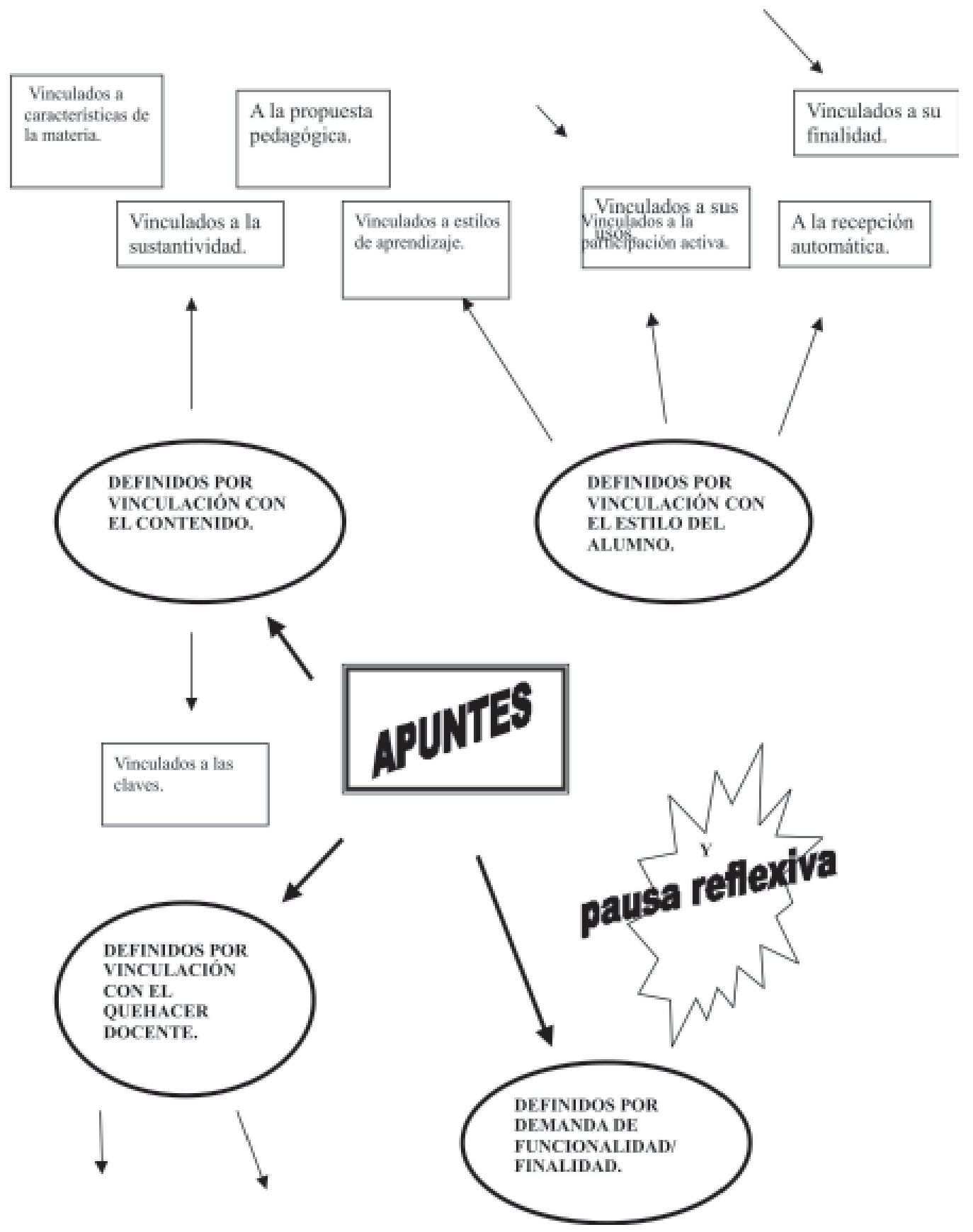

Fig.8 Apuntes. Nuevas dimensiones de análisis. 
El alumno parece como liberado de la responsabilidad de anotar con significación: anota en forma mecánica, sin pensar mucho. También se aprecia, en este aspecto de la recepción automática, una relativa ausencia de planificación previa al contexto de anotación, solamente presente en una actitud manifiesta de "pronto para anotar", en términos de contar con el material necesario.

\section{Apuntes vinculados a la pausa reflexiva.}

La búsqueda de un aprendizaje reflexivo y significativo está mediatizado por diferentes formas de intervención que puedan beneficiar la diversificación y la calidad de los esquemas de conocimiento.

En este orden entendemos que los apuntes pueden ser considerados, precisamente, como una de las formas de intervención, forma que debería ser concientizada para alcanzar el logro de sus objetivos. En este sentido, el aprendizaje reflexivo valora como uno de sus objetivos principales la concientización de los alumnos de sus procesos de aprendizaje y que sean capaces de emplear diversas estrategias de aprendizaje para lograrlo. .

Es así que percibimos una actitud de interés muy presente en reelaborar sus anotaciones, como forma de darle "su sello", su impronta e incorporarlo a sus conocimientos, expresando inclusive, como una forma de "comprometerse con el aprendizaje."

Sin embargo, otros alumnos manifiestan más que una actitud reflexiva, una pausa reflexiva, breve, pero de gran contenido valorativo. Se aprecia en el anotador reflexivo un comportamiento diferenciado en el sentido de que hablan de producciones personales, a las cuales valoran ampliamente. El valor de sus producciones "apuntes", su carácter de fidedignos, les acrecienta su autoestima, estabilizando una actitud de confianza en la actividad que realizan, la cual coopera en posteriores construcciones como forma de asegurarse la correcta información. Estabilizan de este modo una conducta insegura frente a materiales que no son personales. Un sentimiento tan apreciado como la seguridad en sí mismo, es a veces, y en este contexto, proporcionado por el procedimiento de la toma de apuntes.

También ha surgido un aspecto que parece interesante y realmente distintivo: la posibilidad de relacionarse con el contexto áulico, al analizar la actividad desde su perspectiva y considerar como la realizan los otros compañeros, tratan de comprender su postura, justificar y reflexionar respecto a cuáles serían las razones por las cuales los demás las realizan de modo diferente, por ejemplo, automático y no con carácter reflexivo. La proyección del alumno lo lleva en estos casos a incorporar comentarios de sus compañeros, aspecto que no hemos percibido en anotadores con otras características. En este orden, creemos que la actividad de reflexión es tal vez "la pieza maestra" para establecer los enlaces más apropiados y posibles interacciones. ${ }^{\star *}$

\section{Apuntes definidos por el quehacer docente Apuntes vinculados a la propuesta pedagógica del docente.}

Entendemos que, una de las variables emergentes a destacar en el proceso de anotación, es el rol del docente y su propuesta pedagógica. En este orden, determinados factores entran en juego como ser: conocimiento de la materia, la metodología a emplear y su comunicación con los alumnos, factores que a determinados niveles, como ser terciarios, son captados por los estudiantes. Esta revelación, por parte de los alumnos entrevistados, nos debería movilizar en nuestra postura al enfrentar nuestras planificaciones y los diferentes contextos áulicos en los cuales transitamos. 
Apuntes vinculados a las características de la materia.

En ciertos casos, apreciamos otras variables a tener en cuenta como podrían ser las características de la materia y su relación con el tema. En asignaturas en las que el discurso del docente verbaliza más que en otras, porque así lo demanda la materia cuyo enfoque es más propicio a la elocuencia, perciben que se realiza una mayor anotación.Sin embargo, otros estudiantes manifiestan que no sería la materia la determinante de la anotación sino que la temática a desarrollar -aunque estos son losmenos-.

\section{Apuntes definidos por demandas de finalidad y funcionalidad}

Otro factor que se aprecia como coadyuvante en la decisión de toma de apuntes, estilos, formatos, refiere a los usos que se les estaría dando, como también a los propósitos u objetivos que llevan al estudiante a realizar dicha actividad. Al respecto existen determinadas semejanzas como meros registros por diferentes motivos: por desconocer el tema; para retener escrita la información para usos posteriores; como forma de recordatorio.

Otras similitudes se dan en la utilización de los mismos: para uso selectivo de la información, para posteriores integraciones con textos sugeridos por el docente que darán lugar a una nueva construcción de significados, para reproducir información, donde conservan la estructura realizando anotaciones prácticamente literales.

\section{Apuntes vinculados a propósitos.}

Se desprende de las fuentes en estudio que los alumnos reconocen la existencia de razones para tomar notas, es decir no existiría una confusión respecto a que efectivamente lo realizan con determinados propósitos, manifestando coincidencias referentes a armar temas, soportes, verificación de conocimientos, guías orientadores de la comprensión.En este proceso de armar aparece como involucrado un aprendizaje que se diferencia, el estudiante reordena la información, la integra con estructuras cognoscitivas ya existentes y reorganiza, transforma, acercándose así a un contenido significativo.

\section{Apuntes vinculados a sus usos.}

Al realizar las entrevistas se percibe cómo los alumnos expresan que efectivamente los apuntes les son útiles, en el momento de recordar o de armar temas. E inclusive ante el cuestionamiento hipotético de qué harían si los perdieran, manifiestan un sentimiento de desazón todavía mayor ante la posibilidad de prestarlos.Precisamente, esos alumnos que notoriamente expresan una actitud reflexiva, son los que manifiestan su uso en términos de soporte, y a la vez son lo que en alguna medida han tenido acceso o acercamiento al conocimiento de formas de anotaciones estratégicas. Todo esto nos hace pensar que, en ese sentido, la instrucción en formas de anotación sería una importante temática a considerar en la formación de los estudiantes a nivel terciario.

Creemos que si para ellos son tan útiles, como para que les dan tanto valor, ¿por qué razón, nosotros como docentes, tenemos solamente meras sospechas de su utilidad y no estamos al tanto de si hubieran o no mejores formas de realizarlos y de que cooperen en la construcción del conocimiento? ¿O quizás nuestra propia biografía escolar ha marcado a la toma de apuntes, como una estrategia al margen, de borde en el aprendizaje? 


\section{Conclusiones:}

"Lo que los apuntes y alumnos podrían generar"

"....los apuntes son mi vida,..." Ent 8 ..

"Los apuntes son mi Biblia, allí está todo lo que necesito..." Ent 9.

Los estudios, investigaciones realizadas referentes a procesos de Enseñanza y Aprendizaje dan cuenta de gran riqueza de enfoques y perspectivas. Sin embargo, en lo que refiere a estudios realizados referentes a toma de apuntes, como un procedimiento interdisciplinario, o sea, utilizado en diversidad de asignaturas, de contundente utilidad, son relativamente escasos. Por un lado, nos cuestionamos y no tenemos respuesta, por qué razón han sido dejados al margen como temas de investigación, cuando en realidad conocer como registran los alumnos es precisamente conocer una de las formas de conocer a nuestros alumnos. Por otro lado, los estudios a los cuales se ha accedido, dan cuenta de una tradición de anotadores o apuntadores "copistas", es decir que no emplean habilidades de selección de estrategias, cuando realizan sus registros.

En este orden, nuestro trabajo apuntó a correr el velo y penetrar en la realidad social educativa de nuestro siglo XXI y en un contexto específico, el de Formación Docente en el cual se mueven estos alumnos.

En este sentido, nos atrevemos a afirmar que: La construcción final a la que arriban estos alumnos estaría signada, en nuestra opinión, por su toma de apuntes.

Creemos que una toma de apuntes realizada en forma estratégica o ideal como lo planteamos en el marco teórico, podría canalizar la elaboración de constructos genuinos en nuestros jóvenes, y que aquellos que sí utilizan estilos más personalizados, donde las inferencias y reflexiones están presentes, avizoran un crecimiento que se acompasa con lo modernos estudios referentes a Teorías de Aprendizaje donde se revaloriza la comprensión y se recrean significados.

Avizoramos que los apuntes tomados en forma reflexiva modificarían el aprendizaje , alcanzando niveles de mayor abstracción, citando a Monereo (2000) quien expresa que dichos andamiajes les podrían proporcionar una función epistémica y constructiva a las notas.

Percibimos que el desconocimiento de su estructuración, como también de su marco organizativo, se sitúa en relación inversa a la ponderación del aprendizaje. Sin duda que no podemos dejar de reconocer la relación que tienen con su rendimiento, en el cual precisamente los alumnos (la minoría) cuyos apuntes presentan las características de estratégicos, son los que han obtenido mejores rendimientos y han demostrado un mayor nivel participativo y más rico en su recorrer en las aulas.

Se comienzan a evidenciar incursiones en el empleo de ciertas estrategias, lo cual revela una inquietud, un desequilibrio y un no querer aceptar el aprendizaje memorístico, libresco, anotaciones literales. Perciben la incidencia en la construcción de su conocimiento, como soporte guía e inclusive reconociéndoles a sus notas un valor muy superior a otras estrategias utilizadas, refiriéndose a ellas como"mi vida", mi Biblia".

Expresan visiblemente su interés por un aprendizaje de estrategias en la toma de apuntes, y manifiestan una demanda que no deberíamos dejar de atender, voces que no deberíamos dejar de escuchar, de un "desequilibrio en busca de equilibrio" que no se impone desde fuera ni de arriba, sino que es intrínseco y propicia buenas nuevas. Como toda actividad humana las experiencias vividas dejan su huella, su marca, forman parte de nuestra memoria, por lo que entendemos que efectivamente la forma, el modo, estilo, las razones que llevan a la toma de apuntes influyen en el crecimiento del alumno. Por otro lado, determinados estilos que se caracterizan por incoherencias, incongruencias, sin posteriores elaboraciones, dejarán sombras tenues en las mentes de esos alumnos. 
Entendemos que una posible determinación, una "pausa reflexiva", una posible teorización sobre la toma de apuntes podría redundar en su propio beneficio, aportando significación a sus notas y cooperando en la construcción de su cognición , no solo en términos de acumulación de información, sino como una verdadera construcción de conocimientos. Construcción que apele a utilización de conocimientos previos; integración de nuevas habilidades y competencias para finalmente en ese "continuum" lograr la transferibilidad del conocimiento.

Sin duda que, pensamos que como investigador hemos salido fortificados de la experiencia de investigación. Una cuestión a la cual no le conocíamos aristas, nos ha movilizado en múltiples facetas. Las nuevas aristas y complejidades que se han ido agregando al tema nos hacen pensar en futuros campos de estudio e investigación.

La apreciación inicial de la docente cuestionada al respecto con la cual iniciamos nuestro trabajo de investigación:" ahora lápiz y papel en mano...." nos colocó en una posición de desear indagar, por creer que no es posible que una actividad áulica a la cual le hemos dedicado gran parte de nuestro tiempo, nuestras vidas, especialmente durantenuestra formación, califique con comentarios tan peyorativos.

¿Estaríamos, como docentes, dejando al margen una estrategia de gran potencial, reconocida y valorada por los alumnos como tal, como" mi vida", mi Biblia", quienes por otro lado, expresan su desconocimiento respecto de nuevas formas que les posibiliten el camino entre recibir significados y crearlos?

Nos cuestionamos respecto a su relación con la construcción del conocimiento, quizás no tengamos aún todos los elementos de juicio para lograr responder a tales interrogantes, pero sí vislumbramos la posible diferencia entre construir información y conocimientos, entre situar a la toma de apuntes como estrategia de margen y situarla como estrategia de "FONDO".Estrategia que les permita tomar distancia entre la información que se les proporciona y la toma de apuntes, y a través de optimizar recursos de aprendizaje, la breve pausa reflexiva que apreciamos presente en algunos casos, se amplíe a todos y se vuelva un espacio mayor y que fecunde en una toma de apuntes más valiosa para su producción de conocimiento.

De ser posible, optimizar el conocimiento de estos procedimientos en el contexto educativo del Uruguay, a través de prácticas que conduzcan a utilizar los apuntes como estrategias de fondo, y que podrían conducirnos a favorecer la concepción del aprendizaje con una visión más constructivista, como lo reclaman los nuevos tiempos. 


\section{Bibliografía}

ANDER EGG, E. 1995. Técnicas de investigación Social. 24ta ED Buenos Aires: Lumen. ALLWRIGHT, D. 1988. Observation in the language classroom. 2da.ed. Nueva York: Longman.

AUSUBEL, D. 1976. Psicología educativa. Un punto de vista cognoscitivo. México: Trillas. BOYATZIS, R. 1998. Transforming qualitative information . California: Sage Publications. CARRETERO, M. 1991. Procesos de Enseñanza y Aprendizaje.Buenos Aires: Aique. CRESWELL, J. 1994. Research Design. Londres: Sage Publications.

DIAZ BARRIGA, F; HERNÁNDEZ, G. 2002 Estrategias Docentes para un aprendizaje significativo. Mexico: Mc Graw -Hill Interamericana.

DREW, S. . En: Teaching in Higher Education 6(3): pp309-328, 2001 Universidad de Sheffield Hallam.

ERICO, M; et al. 2001. La formación continua de los docentes de Inglés y la práctica áulica. Montevideo: Univ.ORT Uruguay.

FENSTERMACHER, G D. 1989.Tres aspectos de la filosofía de la investigación sobre la enseñanza .En: WITTROCK, M.. 1989. La investigación en la Enseñanza. Enfoques, teorías y métodos I. Cap. III. México: Paidós.

GUERRA, H; Mc CLUSKEY, D. 1984. Cómo estudiar hoy .México: Trillas.

HAMILTON, A. 1988. Notetaking system. [On line] [ febrero, 2004 ]. Disponible en Internet: >ttp://www.tag.abc.ca/services /newsletters>.

IMBERNON, F. et al. 1999. La educación en el siglo XXI. Los retos del futuro inmediato. Barcelona: Editorial Grao.

KIEWRA, K. 2002. How classroom teachers can help students to learn and teach them how to learn.. En: Journals of Educational Research. Sept 2002.

KREIS, S. UCTL 1998.Helping students perform Better: Note taking. [ On line] [ Enero 15, 2004.] Disponible en Internet :< http:// www study.edu.uctl/notes kreis.html>.

MILES, M. B; HUBERMAN, A. M. 1984 Qualitative data analysis: A source of new methods. Beverly Hills:.Sage Publications.

MONEREO, C. 2000. Tomar apuntes: un enfoque estratégico. Madrid: EditorialAprendizaje

MONEREO, C. 2001. Estrategias de enseñanza y Aprendizaje.Madrid:Grao.

MONEREO, C; POZO, J.I. 2003. La Universidad ante la nueva.Cultura Educativa" .Madrid: Editorial Síntesis.

MEIRIEU, P. 2002 .Aprender sí, pero ¿cómo? 3ra.ed. Barcelona: Octaedro

NUNAN, D. 1999.Second language teaching and learning. Boston:Heinle and Heinle publishers.

LITWIN, E. 1997. Las configuraciones didácticas .Buenos Aires: Paidós.

ORNESTEIN, N.2004. [On line] [febrero20, 2004] Disponible en Internet: $<$ http://education.calumet.purdue.edu.vock>.

PARDINAS, F.1998. Metodología y técnicas de investigación en Ciencias Sociales. 35ta. ED.México: Siglo XXI

48 - Universidad ORT Uruguay 
PÉREZ SERRANO, G.1994. Investigación cualitativa. Retos e interrogantes. Madrid: Editorial La Muralla

POZO, J. I. 1995.Aprendices y Maestros. Madrid: Albania.

REID, J. M. 1995. Learning styles in the ESL/ EFL classroom .Boston: Newbury House.

SHULLMAN, J. 1998. Guía para orientar el trabajo en grupo con diversidad en el aula. Buenos Aires: Amorrortu.

STUDENT Academic services.2002 Study skills library. California Polytechnic

State University, San Luis Obispo. [On line] [ Marzo,1,,2004 ]. Disponible en Internet:

<http://www.sas.carpory.edu/asc/ssi/notetaking. Systems.html>.

STENHOUSE, L. 1996.La investigación como base de la enseñanza. Madrid: ED Morata.

TEACHING.2002 Students to take better Notes. University of Nebraska Lincoln.[ On line] [Marzo, 2004] Disponible en Internet<.http://www.uni.edu.gradstud:GSAP/notetaking .html.>.

TAYLOR, J; BOGDAN, R. 1987 Introducción a los métodos cualitativos en investigación Barcelona: Paidós Básica.

TITSWORTH, B. S. The effects of teacher Immediacy and students' note taking in cognitive Learning. En; Journals of Communication in Education. 10,pp. 14-22. 2001.

VALLES, M. 1997.Técnicas cualitativas de investigación social. Madrid: Editorial Síntesis. WAINERMAN, C. 2000.La trastienda de la investigación. Buenos Aires: Lumiere.

WITTROCK, M.1989. La investigación en la Enseñanza. I Barcelona: Editorial Paidós

\section{Notas y citas}

${ }^{1}$ En este orden, coincidimos con Flecha, R. en Imbernon, F et al.1999. "La educación en la sociedad de la información debe basarse en la utilización de habilidades comunicativas, de tal modo que permita participar más activamente y de forma más crítica en la sociedad. Si pretendemos superar la desigualdad que genera el reconocimiento de unas determinadas habilidades y la exclusión de aquellas personas que no tienen acceso al procesamiento de la información, debemos reflexionar con relación a plantear qué tipo de habilidades se están potenciando en los contextos formativos, y si con ello se facilita la interpretación de la realidad desde una perspectiva transformadora".

${ }^{2}$ Al respecto citamos a Carretero, M.1991. Recientemente ha habido un cambio del paradigma proceso-producto al paradigma proceso- proceso, o proceso de mediación (Doyle, 1979; Evertson, 1980), que representa un paso del tiempo a la tarea, recurriendo a ideas provenientes de la psicología cognitiva. Desde esta perspectiva, las tareas que los alumnos emprenden, incluyen, en gran medida, qué información se selecciona del entorno y cómo se la procesa. Las tareas organizan la experiencia, y los investigadores que quieren estudiar y entender esa experiencia,y sus procesos de adquisición, deben por lo tanto entender antes las tareas en que se involucran los alumnos".

${ }^{3}$ Reafirmando dicha postura Monereo, C. y Pozo J. 2003. Manifiesta "tomar notas y apuntes constituye la actividad intelectual a la cual la mayoría de los estudiantes universitarios dedican su mayor tiempo." 
${ }^{4}$ La respuesta de Nunan, D.1999, señala, en estudios realizados por Jones et al. (1987) que los aprendices "más efectivos eran aquellos quienes eran conscientes del proceso subyacente a su propio aprendizaje y de ese modo buscaban emplear las estrategias más apropiadas para controlar su aprendizaje."

${ }^{5}$ Litwin, E.1997. "El conocimiento de una persona no solo se encuentra en la información que almacena o en sus habilidades y actuaciones concretas, sino también en los apuntes que toma , los libros que elige para consulta,,Ios amigos que son sus referentes"

${ }^{6}$ Nos referimos a Meirieu, P.2002 "una actividad que os permita apropiaros de algo nuevo, debéis utilizar capacidades muy precisas y ponerlas en juego... en particular la capacidad para aislar una idea esencial...", capacidad ... que se refiere a la idea mental que llamamos inducción".

7 Porque a mí me cuentan más las cosas, me queda más que mirando". Entrevistado 6

${ }^{8} \mathrm{He}$ visto compañeras que anotan desde que el profesor dice "buen día" hasta que se va y a mí eso me parece que no..."Entrevistado .5

${ }^{9}$ Pozo, J.1995."La naturaleza del sistema cognitivo humano hace que el aprendizaje dependa del buen funcionamiento de ciertos procesos que optimizan o minimizan la eficacia de los procesos de aprendizaje en sí, incrementando las posibilidades de lograr cambios que duren y se generalicen lo más posible."

*El Artículo se enmarca en la tesis de maestría de la autora, dirigida por la Dra. (Cand.) Mariana Maggio. Año 2005.

**Master en Educación, Universidad ORT Uruguay. Diploma en Educación, Universidad ORT Uruguay. Diploma ATCL Associate Trinity College London Diploma, Sheffield University. Maestra en Educación común, Instituto de Formación Docente de Artigas. Profesora de Inglés a nivel Oficial y Privado. Directora de Instituto de Idiomas. Docente Capacitador, Plan 94 Centro Regional Profesores del Litoral. 